\title{
Rotating flow over a stretching sheet in nanofluid using Buongiorno model and thermophysical properties of nanoliquids
}

\begin{abstract}
The boundary layer flow and heat transfer in rotating nanofluid over a stretching sheet using Buongiorno model and thermophysical properties of nanoliquids is studied. Four types of nanoparticles, namely silver ( $\mathrm{Ag})$, copper $(\mathrm{Cu})$, alumina (A12O3) and titania (TiO2) are used in our analysis with water as the base fluid (Prandtl number, $\operatorname{Pr}=6.2$ ). The nonlinear partial differential equations are transformed into ordinary differential equations by using the similarity transformation. The numerical solutions of these equation is obtained using shooting method in Maple software. The numerical results is concentrated on the effects of nanoparticle volume fraction ü, Brownian motion $\mathrm{Nb}$, thermophoresis $\mathrm{Nt}$, rotation $\mathrm{q}$ and suction $\mathrm{S}$ parameters on the skin friction coefficient and heat transfer rate. Dual solutions are observed in a certain range of the rotating parameter.
\end{abstract}

Keyword: Rotating flow; Stretching sheet; Buongiorno model; Nanoliquids 